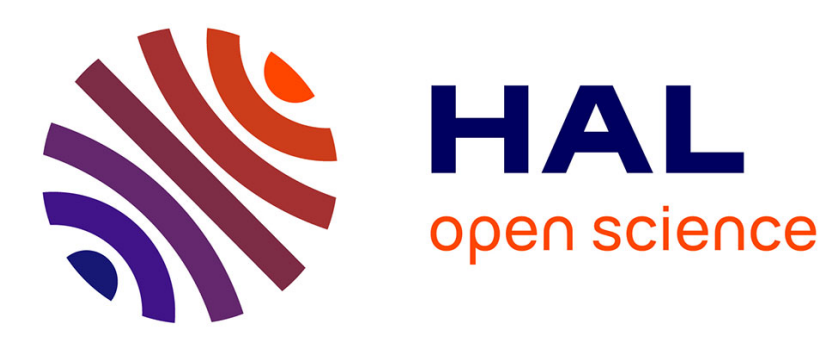

\title{
Experimental study of acoustic anisotropy and birefringence in dry and saturated Fontainebleau sandstone
}

\author{
M. Zamora, J. P Poirier
}

\section{- To cite this version:}

M. Zamora, J. P Poirier. Experimental study of acoustic anisotropy and birefringence in dry and saturated Fontainebleau sandstone. Geophysics, 1990, 55 (11), pp.1455-1465. 10.1190/1.1442793 . insu-01771614

\section{HAL Id: insu-01771614 \\ https://hal-insu.archives-ouvertes.fr/insu-01771614}

Submitted on 19 Apr 2018

HAL is a multi-disciplinary open access archive for the deposit and dissemination of scientific research documents, whether they are published or not. The documents may come from teaching and research institutions in France or abroad, or from public or private research centers.
L'archive ouverte pluridisciplinaire HAL, est destinée au dépôt et à la diffusion de documents scientifiques de niveau recherche, publiés ou non, émanant des établissements d'enseignement et de recherche français ou étrangers, des laboratoires publics ou privés. 


\title{
Experimental study of acoustic anisotropy and birefringence in dry and saturated Fontainebleau sandstone
}

\author{
M. Zamora* and J. P. Poirier ${ }^{\star}$
}

\section{ABSTRACT}

The velocities of ultrasonic $P, S H$, and $S V$ waves have been measured in two perpendicular directions, in samples of Fontainebleau sandstone as received or thermally cracked, dry, or saturated, under uniaxial stress. We have investigated the effect of cracking, saturation, and uniaxial stress on the velocity of $P$ and $S$ waves in two orthogonal directions (anisotropy) and the velocity of $S$ waves with two orthogonal polarizations in each direction of propagation (birefringence). The effect of cracking, saturation, and uniaxial stress on Poisson's ratio has also been investigated.

The velocity anisotropy is larger for $S$ waves than for $P$ waves and practically disappears in saturated samples. Birefringence is attenuated in saturated samples.

Inversion of the results using Crampin's model gives values of the crack densities in three directions, in qualitative agreement with the state of cracking observed by scanning electron microscopy. In particular, the crack density is found to be near zero in sandstones with rounded pores only. After thermally induced cracking the crack density is found to be $\approx 20$ percent; uniaxial stress closes the cracks in the plane normal to the stress. Also, in naturally cracked samples the crack density is found to be quite high. Uniaxial stress causes the density of cracks to decrease, mostly in the plane normal to the stress.

\section{INTRODUCTION}

In recent years, $S$ waves have been increasingly used, together with $P$ waves, for formation evaluation (e.g., Polskov et al., 1980).

In addition to the information on the nature of bright spots derived from the comparison of $P$ and $S$ seismic profiles (Ensley, 1985; McCormack, 1984), the knowledge of $S$ - and
$P$-wave velocities in principle gives access to the whole elastic description of the formation. This in turn could give information on the lithology, through the $V_{P} / V_{S}$ ratio (Tatham, 1976).

Rocks are naturally cracked (Kranz, 1983) and the elastic state of a rock depends much more on the density, aspect ratio, and spatial distribution of cracks and on whether they are dry or saturated than on the elastic moduli of the constituent minerals (Kuster and Toksöz, 1974). Information on these parameters is contained in the anisotropy of velocity and the birefringence of $S$ waves (Crampin, 1978, 1987).

Ideally, knowing $V_{P}, V_{S V}$, and $V_{S H}$ in several directions, we would like to infer the geometry of the crack population and the state of saturation. There is no unique solution to this problem (Nur, 1971), but to achieve at least some understanding, it is necessary to obtain systematic, controlled experimental information and models to interpret it.

Since the pioneering experiments of Nur and Simmons (1969), there have been few laboratory experiments (Gupta, 1973; Tilmann and Bennett, 1973; Bonner, 1974; Rai and Hanson, 1988) to measure $V_{P}, V_{S V}$, and $V_{S H}$ in various directions on the same sample. Nur and Simmons also introduced uniaxial stress as a way to alter the distribution of cracks in a controlled fashion and thus retrieve more information.

There is, however, no dearth of models, even if, of necessity, they have to be oversimplified. They usually start from Eshelby's (1957) ellipsoidal inclusion model and consider a distribution of dilute penny-shaped cracks (Nur, 1971) or a system of noninteracting cracks parallel to one plane (Anderson et al., 1974). The self-consistent approach of O'Connell and Budiansky (1974) waives the requirement of dilute concentration of cracks but considers only an isotropic, random distribution. Crampin (1978) starts from the Garbin and Knopoff (1973, 1975a,b) model and calculates the effect on velocities of a population of noninteracting cracks parallel to three orthogonal planes. Hudson (1981, 1988) calculates the mean field in a solid with a dilute distribution of cracks, either random or aligned, and derives

Manuscript received by the Editor February 13, 1989; revised manuscript received April 27, 1990.

*Institut de Physique du Globe de Paris, 4 place Jussieu, 75252 Paris Cedex, France.

${ }^{C} 1990$ Society of Exploration Geophysicists. All rights reserved. 
formulas for the velocities, which agree with Garbin and Knopoff. Sayers (1988) introduces the crack orientation distribution function and uses it to derive the elastic wave velocities in all directions, which in turn can be inverted to yield microfracture pole figures.

In the present study, we simultaneously measured the ultrasonic longitudinal velocity $V_{P}$ and shear-wave velocity $V_{S}$ in Fontainebleau sandstone of various porosities and permeabilities. The measurements were made between both pairs of vertical faces of the sample. The shear-wave velocity is measured for polarization in the vertical plane (called $V_{S V}$ ) and in the horizontal plane (called $V_{S H}$ ). A vertical uniaxial stress is applied and the dependence of the velocities on crack density, saturation, and applied stress is determined.

In cracked samples, the velocities $\left(V_{P 1}, V_{S H 1}, V_{S V 1}\right)$ of the $P$ and the two shear waves traveling normal to one pair of faces are usually different from those $\left(V_{P 2}, V_{S H 2}, V_{S V 2}\right)$ for the waves traveling normal to an orthogonal pair of faces, i.e., $V_{P 1}=V_{P 2}$, etc. We call this feature "the path or the direction dependence" of the velocity. As the vertical applied stress increases, the velocities of the two shear waves traveling in the same direction, either 1 or 2, become different $\left(V_{S H 1}=V_{S V 1}\right.$, etc.). This is the polarization dependence of the shear-wave velocities, described in the literature as "shear-wave birefringence." A material with such properties, i.e., with velocities that depend upon the direction of wave travel and the polarization of its particle motion, is called anisotropic.

A plausible distribution of cracks on three orthogonal planes is deduced, using Crampin's (1978) model for the dry rock.

\section{EXPERIMENTAL PROCEDURE}

\section{The material}

Fontainebleau sandstone is composed of well-rounded quartz grains, about $0.25 \mathrm{~mm}$ in diameter, cemented by silica. It is thus clay free and exceptionally pure $(99.8 \%$ quartz). It is, however, extremely hetereogeneous, and porosity, permeability and state of cracking can vary by considerable amounts over distances of the order of $10 \mathrm{~cm}$. There is, however, no visible bedding.

Fontainebleau sandstone therefore can provide samples with the same mineralogical composition and various permeabilities and porosities ( 3 to 30 percent).

\section{The samples}

Parallelipipedic samples, $5 \times 5 \times 8 \mathrm{~cm}$, are sawn out of sandstone blocks. Their open porosity is measured by saturation under vacuum and their permeability is measured using an air permeameter (Table 1). The pore space is characterized by impregnating a slice of rock adjacent to the sample with fluid epoxy resin, dissolving the quartz in hydrofluoric acid, and examining the replica in a scanning electron microscope. The technique is described in Bourbié et al. (1987).

The faces of the sample are ground to a good finish and, kept parallel to within 0.004 radian, they are cleaned with compressed air and the last specks of fine grit are eliminated by carefully rubbing the surface with a finger.

Four different experiments are successively performed on each sample:

Dry.-The sample is oven dried at $70^{\circ} \mathrm{C}$ for at least 48 hours and slowly cooled to room temperature. A good coupling between sample and transducers is ensured by interposing a thin plastic film (Parafilm PM-992, American Can Company).

Saturated.-The best coupling is obtained by gluing a plate of aluminum ( $1 \mathrm{~mm}$ thick) on all the faces of the sample, with a thin layer of Armstrong A271 glue. The sample is then oven dried for at least $48 \mathrm{~h}$ at $70^{\circ} \mathrm{C}$, cooled to room temperature, and placed in a container under dynamic vacuum ( 0.01 torr) for $5 \mathrm{~h}$. The container is then filled with distilled water and kept open in the oven at $70^{\circ} \mathrm{C}$ for $12 \mathrm{~h}$, allowing air bubbles to escape. It is then cooled to room temperature, completely filled with water, closed shut, and heated again to $70^{\circ} \mathrm{C}$ to build some pressure (about 20 bars for $12 \mathrm{~h}$ ). The sample is then cooled and transferred to the measuring apparatus.

Cracked.-The sample is dried again using the above procedure and introduced in an oven preheated to $400^{\circ} \mathrm{C}$ or $450^{\circ} \mathrm{C}$ where it stays for $10 \mathrm{~min}$. Pervasive cracking occurs due to the thermal expansion anisotropy of quartz. The sample is then taken out of the oven and allowed to cool.

Table 1. Porosity and permeability of the Fontainebleau sandstone used.

\begin{tabular}{|c|c|c|}
\hline Samples & $\begin{array}{l}\text { Porosity } \\
(\%)\end{array}$ & $\begin{array}{l}\text { Permeability } \\
\text { (mD) }\end{array}$ \\
\hline F32 & $8.9^{*}$ & 99 \\
\hline F33 & 8.4 & 99 \\
\hline F6 & 6.5 & 0.3 \\
\hline F7 & 5 & - \\
\hline
\end{tabular}

*after cracking

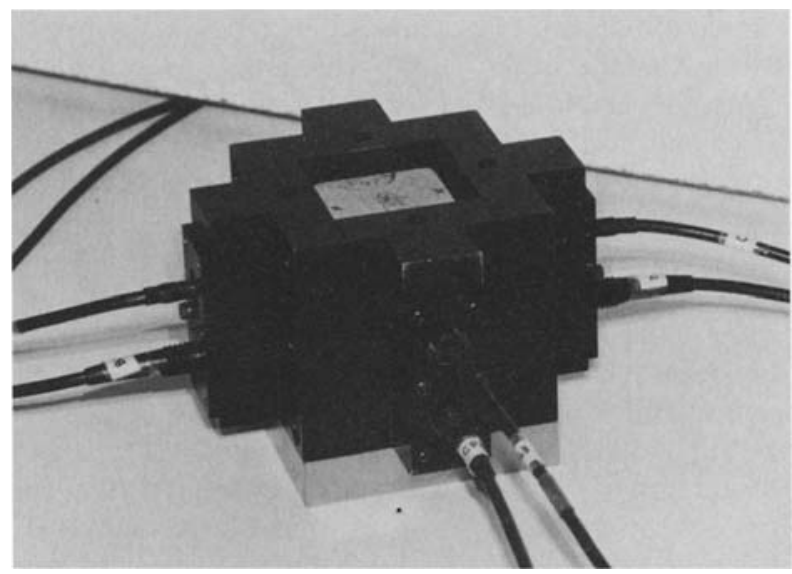

FIG. 1. The experimental setup: The rock sample is seen inserted in the watertight jig. $S$ and $P$ emitter and receiver ultrasonic transducers are fitted in holes on opposite faces. 
Cracked and saturated.-The cracked sample is saturated using the technique described above.

\section{The experimental setup}

The sample is held in a watertight jig into which the ultrasonic transducers are inserted and firmly pressed against the sample with springs (Figure 1). Two pairs of transducers, one for $P$ waves and the other for $S$ waves, are used for each of the vertical orthogonal pairs of faces. Each pair consists of identical $1 \mathrm{MHz}$ Panametrics transducers (V103SB for $P$ and V153SB for $S$ waves), one being used as an emitter and the other as a receiver.

The signal is delivered by a Panametrics 5055PR pulse generator. The output signals are displayed and stored in a five-channel Tektronix 7603 oscilloscope with a digital programmable rack, which can record 1024 points with an 8-bit resolution and a sampling rate up to $50 \mathrm{MHz}$ ( 20 ns between points) (Figure 2). Processing of the signals and final storage of the results are done with a Victor V1 microcomputer.

\section{The experimental runs}

A typical run proceeds along the following lines:

(1) The sample is dried or saturated, its dimensions are measured with $\pm 0.02 \mathrm{~mm}$, and it is then placed in the jig with the $S$ transducers oriented so as to measure the $S V$-wave velocity (polarization plane parallel to the vertical axis of the sample).

(2) The jig is brought between the platens of a $10 t$ Instron mechanical testing machine, and the transit times of $P$ and $S V$ waves are measured in both directions.

(3) A compressive force is then applied to the sample, through a steel block, by the machine at a rate of 100 $\mathrm{kgf} / \mathrm{min}$. When the force reaches $200 \mathrm{kgf}$ (corresponding to a uniaxial stress of about $0.8 \mathrm{MPa}$ ), it is kept constant by a servocontroller and the transit times of $P$ and $S V$ waves are again measured. The procedure is repeated with the compressive force increasing by steps of $200 \mathrm{kgf}$ until a maximal stress is reached, depending on the state of cracking of the sample. The machine is then put in reverse and the procedure is repeated for decreasing uniaxial stress.

(4) The $S$ transducers are then rotated by 90 degrees and the whole procedure is repeated, this time giving transit

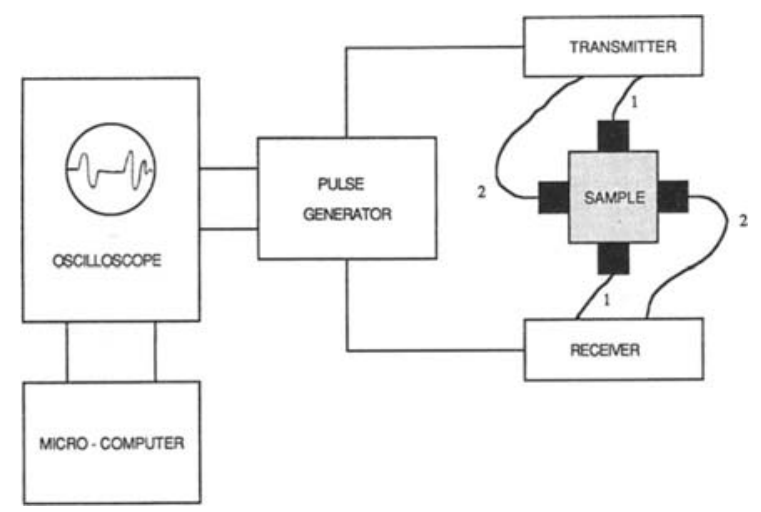

FIG. 2. Principle of the experiment. times of $P$ and $S H$ waves. The $P$-wave velocities are the same in the first and second runs. Together with the fact that the $S$ velocities at zero applied stress differ by less than 2 percent before and after a loading-unloading cycle, this shows that even the maximum applied stress can close or open cracks in a reversible way but cannot create cracks. We give a typical example in Table 2 (sample F32). We are thus justified in comparing $V_{S V}$ and $V_{S H}$ determined in successive runs.

\section{Errors and corrections}

The two sources of error in the determination of the sound velocities are the errors in determination of the length of the path and of the transit time. The length of the path is determined by measuring the width of the sample to within $0.02 \mathrm{~mm}$.

Variation of the width, due to the application of an axial force, is neglected since it is very small (about $20 \mu \mathrm{m}$ for 500 $\mathrm{kg}$ ) and practically the same for all experiments. (Poisson's ratio is indeed quite small as will be apparent later.)

The transit time is measured on the screen of the scope with an accuracy better than $0.2 \mu \mathrm{s}$; it is corrected of the transit time in the transducers and coupling film (for dry specimens) or glue and aluminum plates (for saturated specimens).

The transit time in the transducers and parafilm has been measured; it is $0.402 \mu \mathrm{s}$ for $P$ waves and 0.483 for $S$ waves. In the case of the saturated specimens, the thickness of the film of glue is not necessarily the same in all experiments and we measure the transit times in every case before and after gluing the plates. The wave velocities are then known to within $\pm 0.1 \mathrm{~km} / \mathrm{s}$.

\section{EXPERIMENTAL RESULTS}

\section{Sample F6 (Figure 3)}

This sandstone is hard and dense, with a porosity of about 6 percent and a low permeability $(0.3 \mathrm{mD})$. The grains are equant and the porosity is mostly due to intergranular voids (Figure 4) with a very low crack density. In the dry samples, the velocities are high $\left(V_{P} \approx 5.5 \mathrm{~km} / \mathrm{s}, V_{S} \approx 3.6 \mathrm{~km} / \mathrm{s}\right)$ although somewhat smaller than those of quartz and there is no anisotropy and no birefringence of $S$ waves.

Poisson's ratio is $v \approx 0.12\left(V_{P} / V_{S}=1.52\right)$ in the expected range for quartz rocks (Timur and Toksöz, 1985). The velocities do not vary with applied uniaxial stress and no velocity anisotropy is induced (see Figure 3a).

After 100 percent saturation with water, the velocities change very little (if anything, they would drop by about 5 percent) and Poisson's ratio increases slightly $(v \approx 0.16)$. There is still neither anisotropy nor birefringence and no effect of the applied stress. It is therefore reasonable to conclude that the density of cracks is too low to have any effect on the velocities and that the maximal stress $(\approx 8 \mathrm{MPa})$ is not high enough to open any cracks.

After drying and thermally induced microcracking, the changes in velocity are spectacular (see Figure 3c): $V_{P}$ drops by about 40 percent to $3.3 \mathrm{~km} / \mathrm{s} ; V_{S}$, also considerably lower, becomes anisotropic and birefringence appears. $P$ 


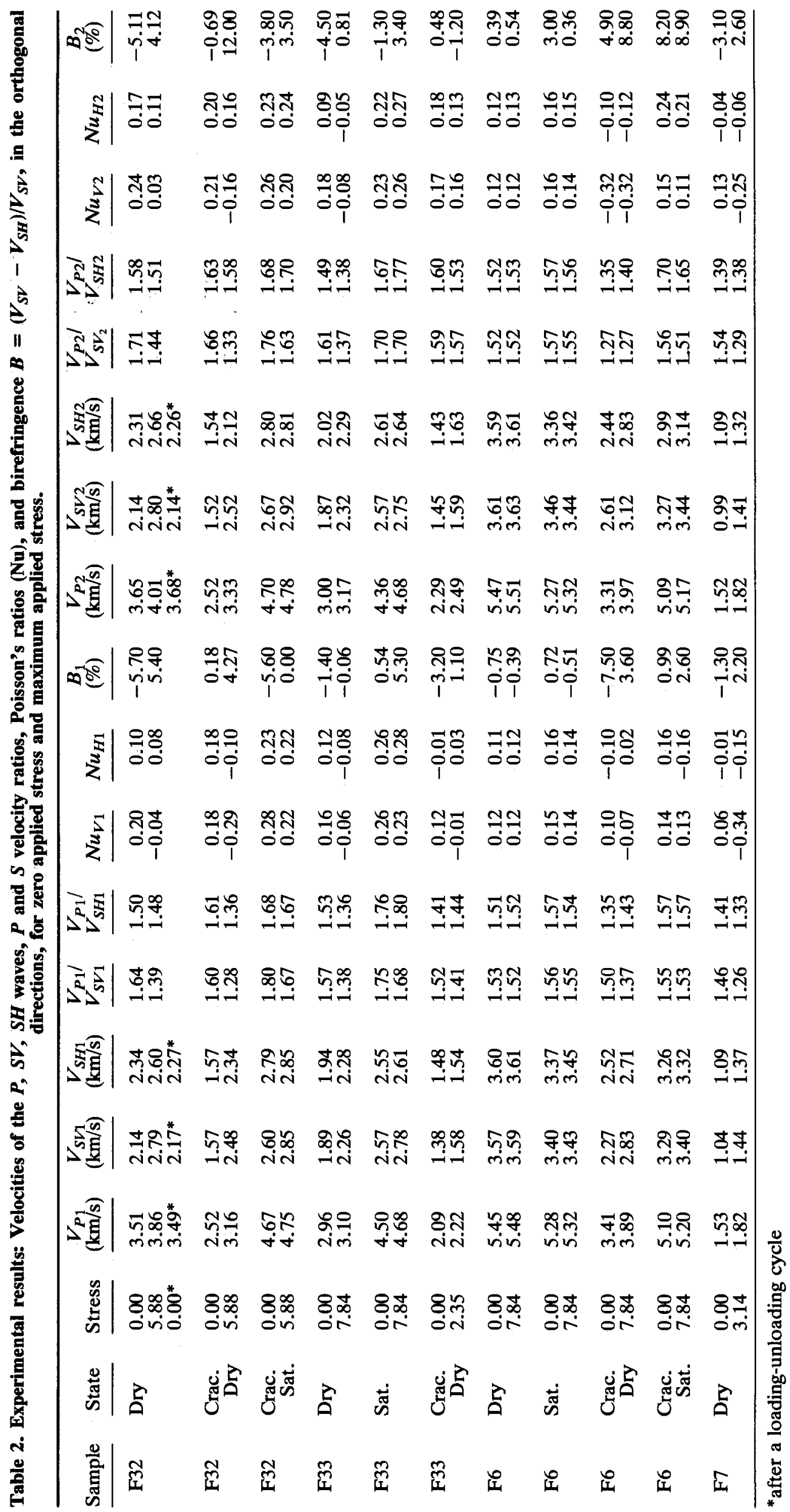



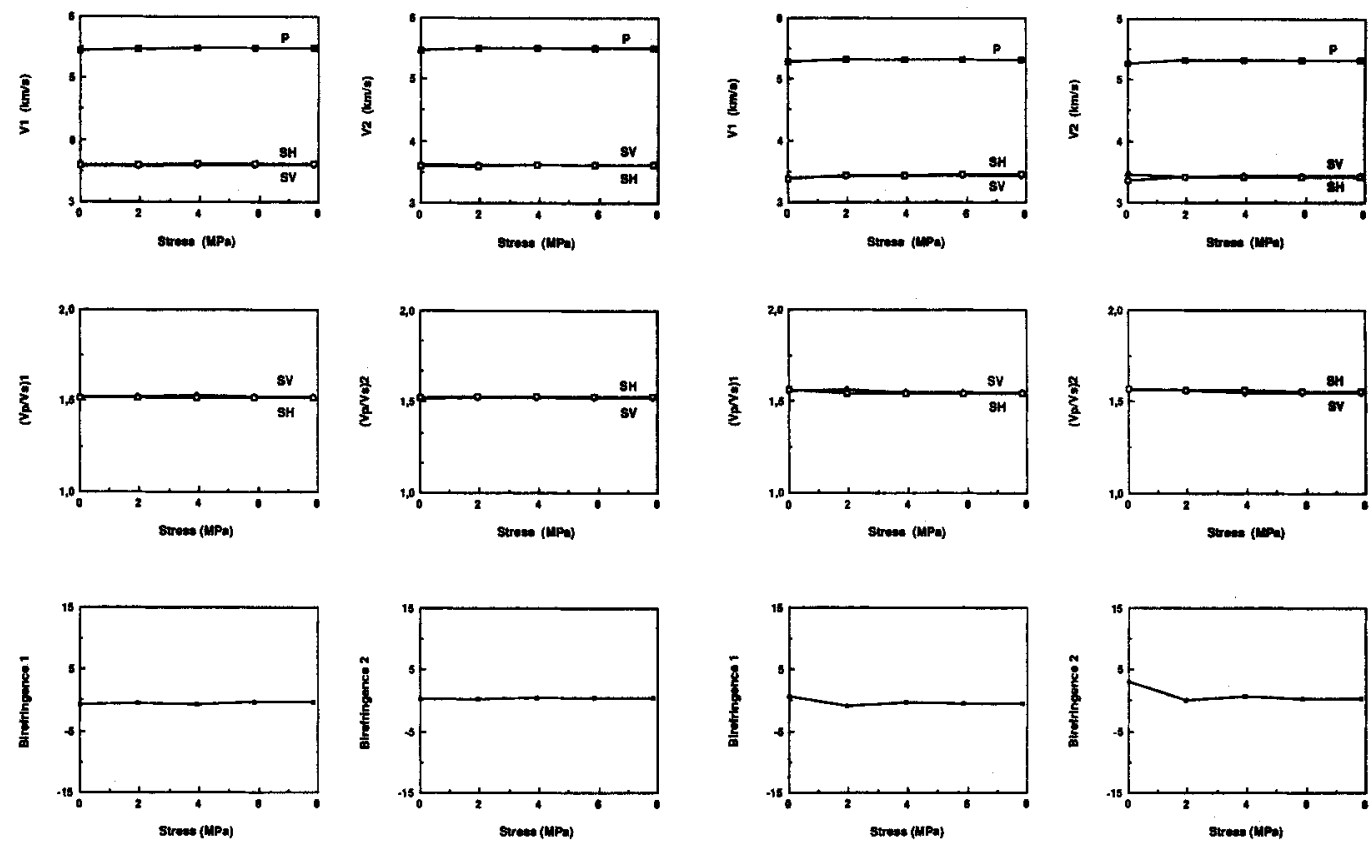

F6 CRACKED DRY
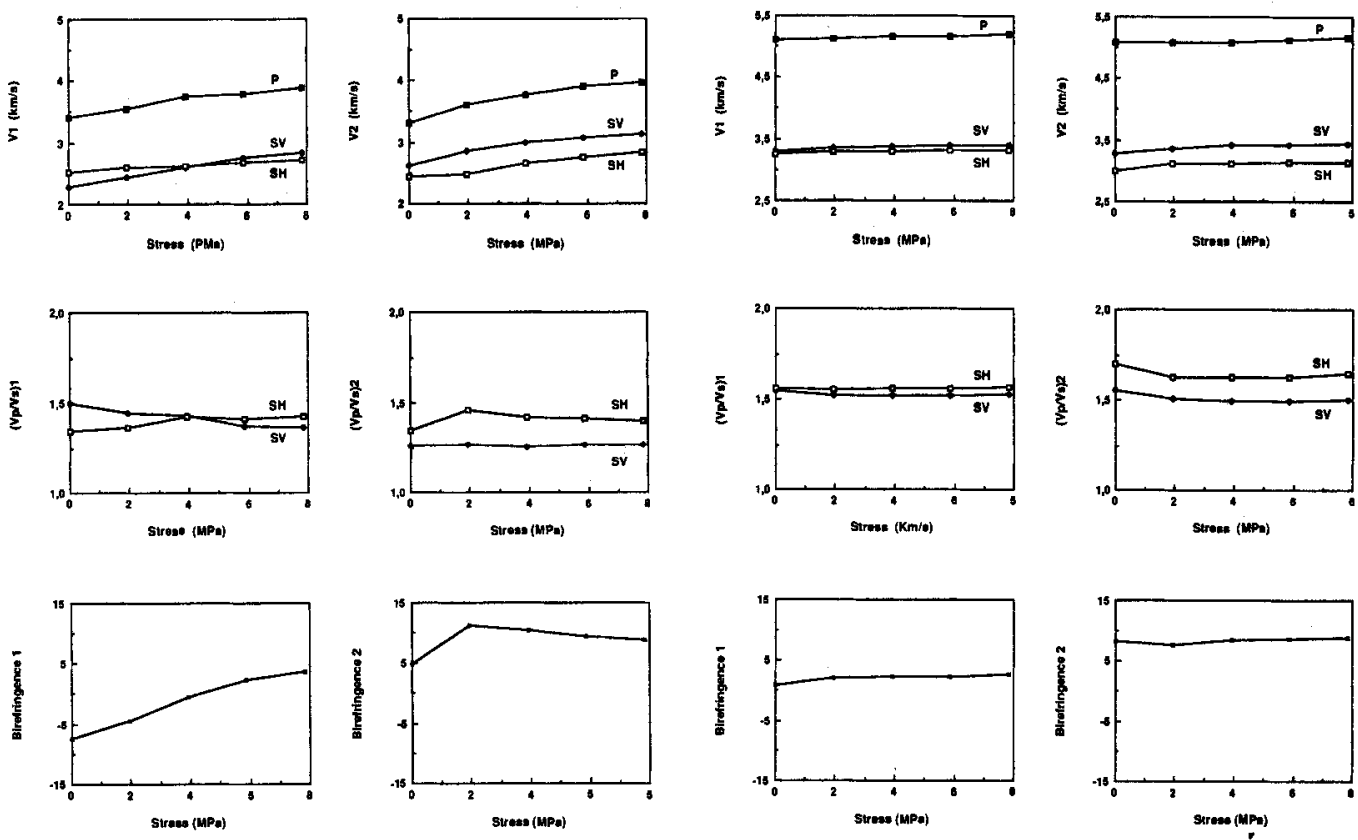

Fig. 3. Sample F6: (a) dry, (b) saturated, (c) cracked dry, (d) cracked saturated. (Top) $P, S V$, and $S H$-wave velocities in orthogonal directions 1 and 2 as a function of the applied uniaxial stress in the vertical direction 3 . Suffix 1 or 2 is used depending on whether the measures is made between pair 1 and 2 of the vertical faces of the sample. (Middle) $V_{P} / V_{S V}$, and $V_{P} / V_{S H}$ ratios in the orthogonal directions 1 and 2 as a function of the applied uniaxial stress. (Bottom) Birefringence $\left(V_{S V}-V_{S H}\right) / V_{S V}$ in the orthogonal directions 1 and 2 as a function of the applied uniaxial stress. 
and $S$ velocities increase with applied stress (about 2 percent per MPa) and Poisson's ratio becomes zero or negative.

Total saturation of the cracked samples brings the velocities back to almost the values they had in the uncracked saturated sample and restores isotropy, except for $V_{S H}$. The effect of applied stress disappears. However, birefringence subsists in one direction, where $V_{S H}<V_{S V}$ as in the dry cracked sample. Poisson's ratio increases up to values higher than those of the uncracked saturated sample $(v \approx$ 0.24). Obviously, as predicted by all models, $V_{P}$ is more sensitive to saturation than $V_{S}$.

\section{Sample F3 (Figure 5)}

The samples F32, F33 have been cut orthogonally from the same block, about $50 \mathrm{~cm}$ at each edge. Despite their proximity, the heterogeneity of the block was such that the expected identity of velocities (e.g., between $V_{P 2}$ in F32 and F33) cannot be found.

The samples are rather heavily microcracked (Figure 6): their velocities are comparable to those of the thermally cracked F6 samples. There is little or no anisotropy and a slight birefringence in the dry samples; the effect of uniaxial stress is smaller than in the case of cracked F6.

Sample F33 developed some degree of anisotropy after thermal cracking but little birefringence. The applied stress had to be kept lower than $3 \mathrm{MPa}$, lest the sample should be damaged. Sample F32 did not become more anisotropic after thermal cracking but its birefringence increased, to disappear again after saturation.

\section{Sample F7 (Figure 7)}

This sandstone exhibits all signs of being heavily microcracked (Figure 8 ), the velocities are extremely low in the dry sample $\left(V_{P} \approx 1.5 \mathrm{~km} / \mathrm{s}\right)$, and Poisson's ratio is about zero. There is no anisotropy to speak of. Birefringence exists but is not very large. The velocities increase with applied stress ( 4 to 10 percent per MPa) but the experiments had to be stopped at $3 \mathrm{MPa}$ for the same reason as with F33.

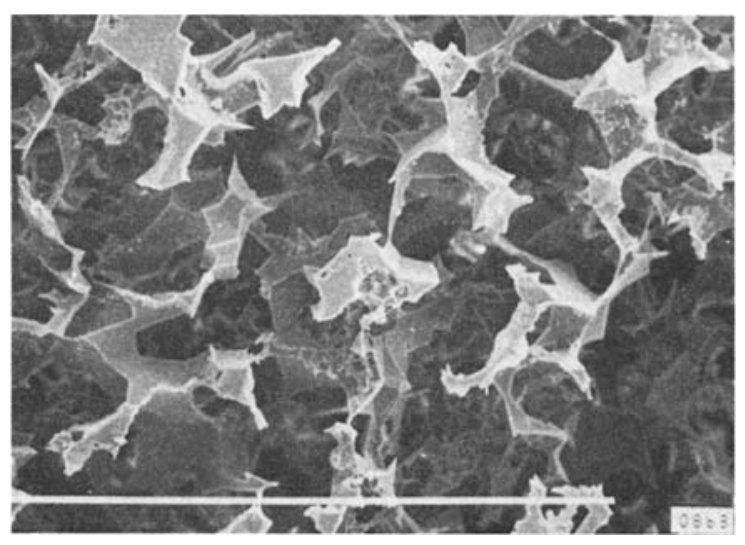

Fig. 4. Scanning electron micrograph of the epoxy replica of sample F6. Porosity consists mostly of angular pores at the triple junctions. Scale bar: $1 \mathrm{~mm}$.

\section{Summary of experimental data}

The experimental results are gathered in Table 2 and can be qualitatively summed up as follows:

For dry samples.-(a) The velocities decrease as the apparent degree of microcracking increases. (b) Poisson's ratio decreases as the apparent degree of microcracking increases, from values typical of quartz rocks for uncracked samples to negative values for heavily cracked samples. (c) Velocity anisotropy seems larger in thermally than in naturally cracked samples and it is usually larger for $S$ than for $P$ waves. (d) The application of uniaxial stress normal to the direction of propagation of the waves causes the velocities to increase slightly (as already observed by Nur and Simmons, 1971; Gupta, 1973; Tilmann and Bennett, 1973; Bonner, 1974; and Rai and Hanson, 1988), hence presumably closing more cracks than it opens; it also causes the birefringence to increase.

For saturated samples. - (a) The velocities increase back to values comparable to those of uncracked samples. (b) Poisson's ratio of saturated cracked samples increases up to values larger than those of uncracked saturated samples. (c) Saturation causes anisotropy to practically disappear. (d) Birefringence is attenuated. (e) The effect of uniaxial stress is practically nonexistent.

\section{INTERPRETATION AND DISCUSSION}

\section{Crampin's model}

We have attempted to interpret our results in the framework of Crampin's (1978) model for multiplanar cracks. This model has the advantage of expressing the velocities along a given direction and for a given polarization of $S$ waves as a function of the densities $\varepsilon_{1}, \varepsilon_{2}, \varepsilon_{3}$ of cracks normal to three orthogonal directions 1,2 , and 3 , of the angle $\theta$ between the propagation direction and the normal to one plane of cracks (e.g., 1), and of the angle $\phi$ between the polarization of the shear waves and the normal to the plane of incidence.

The model is valid for dilute, noninteracting cracks. With this assumption it is possible to derive the total relative velocity changes for a solid with densities of cracks $\varepsilon_{1}, \varepsilon_{2}$, $\varepsilon_{3}$, respectively, normal to axes 1,2 , and 3 by multiplying the individual velocity changes for the cases when the cracks are normal to only one direction.

We thus obtain, for waves propagating along direction 1 ,

$$
\begin{aligned}
V_{P} & =V_{P 0} /\left[\left(1+6 \varepsilon_{1}\right)\left(1+2 \varepsilon_{2} / 3\right)\left(1+2 \varepsilon_{3} / 3\right)\right]^{1 / 2}, \\
V_{S V} & =V_{S 0} /\left[\left(1+16 \varepsilon_{1} / 7\right)\left(1+16 \varepsilon_{3} / 7\right)\right]^{1 / 2}, \\
V_{S H} & =V_{S 0} /\left[\left(1+16 \varepsilon_{1} / 7\right)\left(1+16 \varepsilon_{2} / 7\right)\right]^{1 / 2},
\end{aligned}
$$

and for waves propagating along direction 2 ,

$$
\begin{aligned}
V_{P} & =V_{P 0} /\left[\left(1+6 \varepsilon_{2}\right)\left(1+2 \varepsilon_{1} / 3\right)\left(1+2 \varepsilon_{3} / 3\right)\right]^{1 / 2}, \\
V_{S V} & =V_{S 0} /\left[\left(1+16 \varepsilon_{2} / 7\right)\left(1+16 \varepsilon_{3} / 7\right)\right]^{1 / 2}, \\
V_{S H} & =V_{S 0} /\left[\left(1+16 \varepsilon_{1} / 7\right)\left(1+16 \varepsilon_{2} / 7\right)\right]^{1 / 2} .
\end{aligned}
$$


F32 DRY
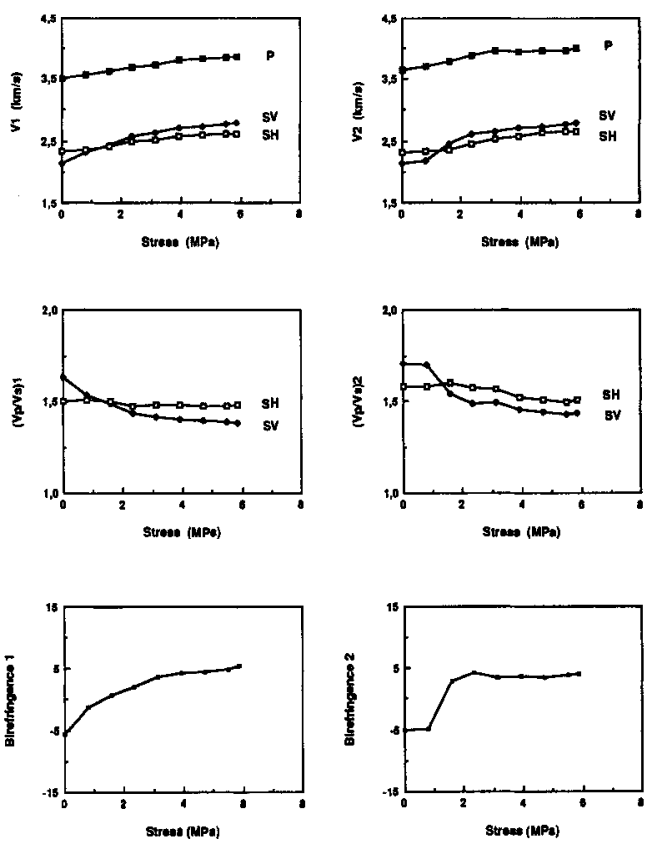

F32 CRACKED DRY
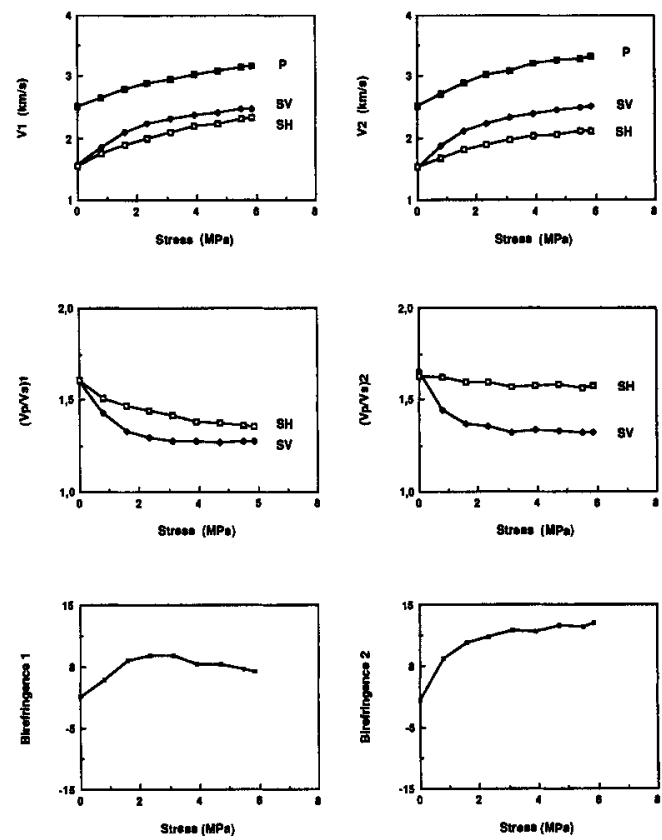

F32 CRACKED SATURATED
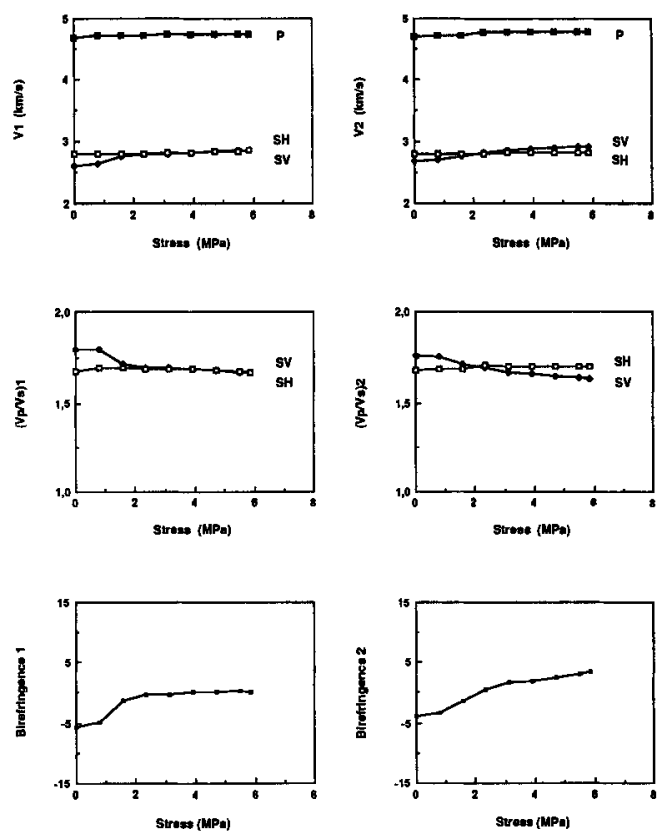

FIG. 5. Sample F32: (a) dry, (b) cracked dry, (c) cracked saturated. (Top) $P, S V$, and $S H$-wave velocities in the orthogonal directions 1 and 2 as a function of the applied uniaxial stress in the vertical direction 3. (Middle) $V_{P} / V_{S V}$ and $V_{P} / V_{S H}$ ratios in orthogonal directions 1 and 2 as a function of the applied uniaxial stress. (Bottom) Birefringence $\left(V_{S V}-V_{S H}\right) / V_{S V}$ in orthogonal directions 1 and 2 as a function of the applied uniaxial stress. 
$V_{P 0}$ and $V_{S 0}$ are the $P$ and $S$ wave velocities in the uncracked (isotropic) rock. We have taken $V_{P 0}=5.8 \mathrm{~km} / \mathrm{s}$, $V_{S 0}=3.349 \mathrm{~km} / \mathrm{s}$ (Crampin, 1978).

Since we apply the uniaxial stress along direction 3 , it was not possible with our present experimental setup to measure the velocity changes along direction 3 .

For the case of saturated cracks, Crampin's model only allows for the effect of the bulk modulus of the saturating fluid. As a consequence, it predicts the same velocity for $S H$

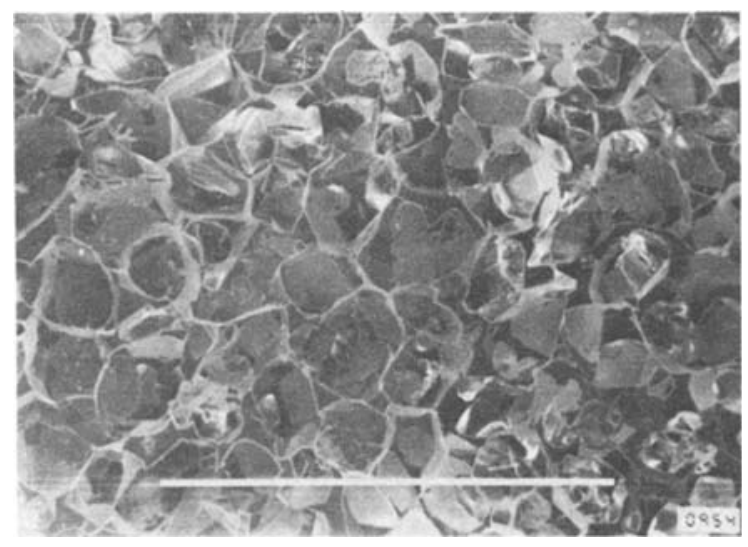

FIG. 6. Scanning electron micrograph of the epoxy replica of a sample F3. Porosity is in the form of flat intergranular cracks and pores at the triple junctions. Scale bar: $1 \mathrm{~mm}$.

F7 DRY
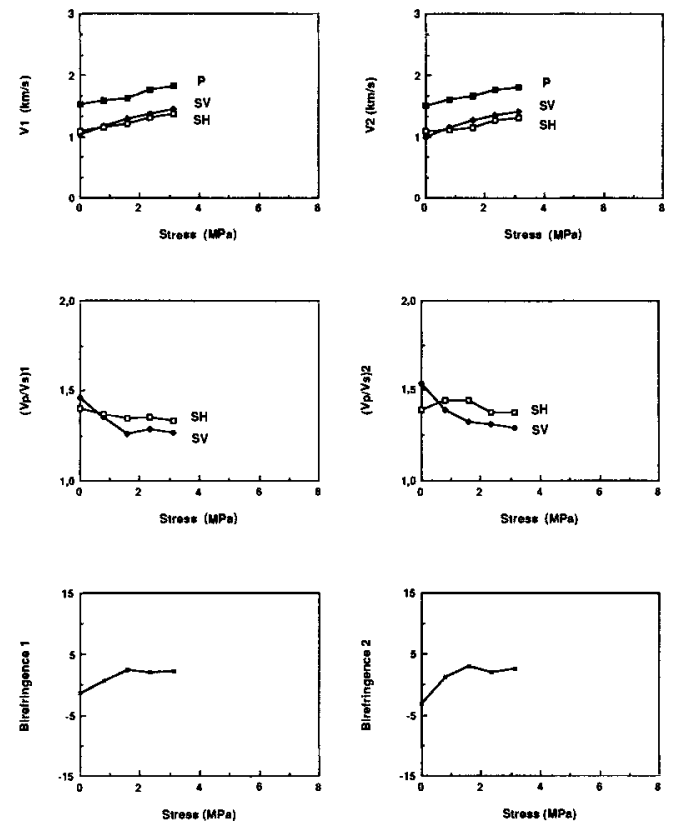

FIG. 7. Sample F7 dry. (Top) $P, S V$, and $S H$-wave velocities in orthogonal directions 1 and 2 as a function of the applied uniaxial stress in the vertical direction 3. (Middle) $V_{P} / V_{S V}$ and $V_{P} / V_{S H}$ ratios in orthogonal directions 1 and 2 as a function of the applied uniaxial stress. (Bottom) Birefringence $\left(V_{S V}-V_{S H}\right) / V_{S V}$ in orthogonal directions 1 and 2 as a function of the applied uniaxial stress. and $S V$ waves, i.e., no birefringence, and it clearly does not apply to our experimental results. We therefore limited ourselves to interpreting our results in dry specimens only.

The main problem we encounter in trying to model our results in terms of anisotropic crack populations is that Crampin's model, as indeed all such models, applies in principle only to dilute noninteracting cracks. It would be clearly unrealistic to make the assumption that the crack population is dilute, either in our naturally or thermally cracked samples (see Figures 6 and 8). However, we have (admittedly unwarrantedly) used the model to calculate velocity changes for high crack concentrations and qualitatively compared the predictions to our experimental results in the simple case where $\varepsilon_{1}=\varepsilon_{2}$ (lateral isotropy) for decreasing values of $\varepsilon_{3}$ (corresponding to increasing values of the uniaxial stress which closes cracks normal to direction 3). We can see by comparing the predicted variation of $V_{P}$, $V_{S V}, V_{S H}, V_{P} / V_{S H}, V_{P} / V_{S V}$, and birefringence (Figure 9) to the results for samples F32 dry, for instance (Figure 5), that there is good qualitative agreement: $V_{S V}$ increases faster than $V_{S H}$ when the stress increases (or $\varepsilon_{3}$ decreases) and, consequently, $V_{P} / V_{S V}$ decreases faster than $V_{P} / V_{S H}$ and birefringence increases.

We therefore decided to try to invert our results, using Crampin's model even though we obviously would find crack densities much higher than the limits of validity of the model.

\section{The inversion method}

We inverted our results by searching for the maximum of the Bayesian probability density in the $\varepsilon_{1}, \varepsilon_{2}, \varepsilon_{3}$ space (Tarantola, 1987). We give only the principle of the method here and refer the reader to Tarantola (1987).

We take as our data in data space $d$ the six values:

$$
d_{i \mathrm{obs}}=\log \left(V_{P o} / V_{P i}\right) \quad 1 \leq i \leq 6
$$

corresponding to $V_{P}, V_{S V}, V_{S H}$ in directions 1 and 2 . If we assume the data are known with Gaussian errors and that the errors are uncorrelated, the probability density in data space can be written

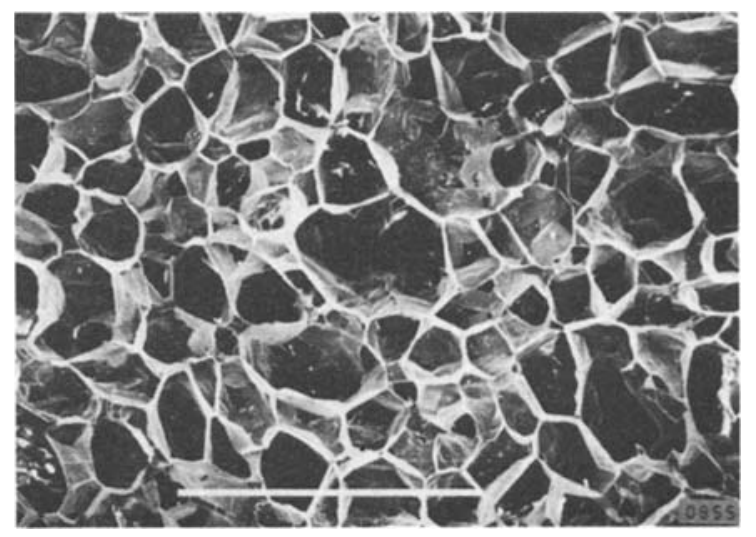

FIG. 8. Scanning electron micrograph of the epoxy replica of a sample F7. Porosity is mostly in the form of flat intergranular cracks. Scale bar: $1 \mathrm{~mm}$. 


$$
P(d)=k \exp \sum_{1}^{6}-\left(d_{i}-d_{i \text { obs }}\right)^{2} / \sigma_{i}^{2}
$$

where $\sigma_{i}$ is the standard deviation of the experimental velocity measurements. It can be shown that the probability density in model space (crack densities $\varepsilon_{1}, \varepsilon_{2}, \varepsilon_{3}$ ) is

$$
P(m)=P\left(d_{\text {calc }}\right),
$$

where $d_{\text {calc }}$ is obtained by the exact solution of the forward problem. Here we use equations (1) and (2) and we have, for instance,

$$
\varepsilon_{1}=\varepsilon_{2}=0.25
$$
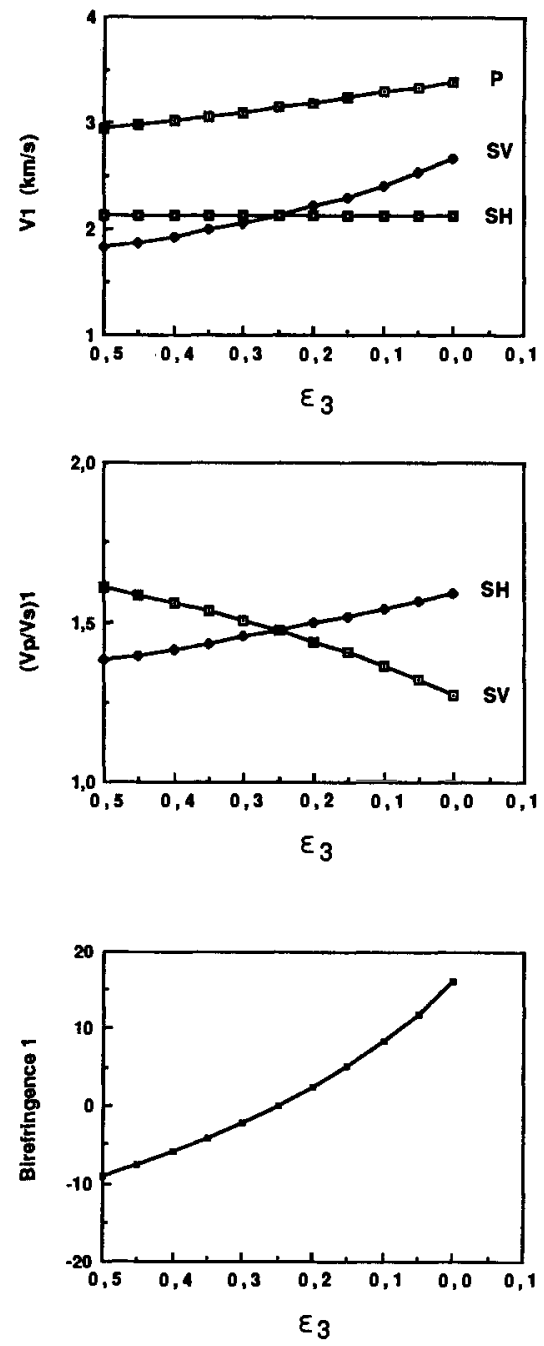

FIG. 9. $P, S V$, and $S H$-wave velocities; $V_{P} / V_{S V}, V_{P} / V_{S H}$ ratios and birefringence as a function of the crack density $\varepsilon_{3}$, calculated with Crampin's model in the case where the crack densities normal to the two orthogonal horizontal directions in which the velocities are measured are equal: $\varepsilon_{1}=\varepsilon_{2}=$ $\varepsilon=0.25$. The crack density $\varepsilon_{3}$ corresponds to horizontal cracks. The crack density decreases toward the right to allow comparison with the case where a vertical uniaxial stress (increasing toward the right) is applied, closing the horizontal cracks. (Compare to Figure 5).

$$
\begin{aligned}
d_{1 \mathrm{calc}}= & 1 / 2\left[\log \left(1+6 \varepsilon_{1}\right)+\log \left(1+2 \varepsilon_{2} / 3\right)\right. \\
& \left.+\log \left(1+2 \varepsilon_{3} / 3\right)\right], \text { etc. }
\end{aligned}
$$

We therefore have

$$
\begin{aligned}
& P\left(\varepsilon_{1}, \varepsilon_{2}, \varepsilon_{3}\right) \\
& \quad=k \exp -\left[0.5 \sum_{1}^{6}\left(d_{i \text { calc }}\left(\varepsilon_{1}, \varepsilon_{2}, \varepsilon_{3}\right)-d_{i \text { obs }}^{2}\right)^{2} / \sigma_{i}^{2}\right] .
\end{aligned}
$$

The best values of $\varepsilon_{1}, \varepsilon_{2}, \varepsilon_{3}$ fitting the data are obtained by searching for the maximum of $P\left(\varepsilon_{1}, \varepsilon_{2}, \varepsilon_{3}\right)$. This is achieved by inspecting computer-produced contoured maps of $P$ in $\varepsilon_{2}, \varepsilon_{3}$ space for various values of $\varepsilon_{1}$ (Figure 10). The best value of $\varepsilon_{1}$ is the one for which the maximum of $P$ is the greatest and $\varepsilon_{2}$ and $\varepsilon_{3}$ are read as the coordinates of this maximum.

Note that one of the assumptions on which the inversion method rests is that there are no modelization errors, which obviously is far from being the case. Nevertheless, although the results exhibit various unacceptable features (such as the total density of cracks being occasionally greater than 1) we feel that there is some merit in this approach in that it gives a reasonable idea of the respective importance of the crack densities in the three directions and that it correctly accounts for the closure of cracks in direction 3, as well as for the evolution of $V_{P} / V_{S}$ and birefringence with cracking (Table 3).

\section{Discussion}

Inspection of Table 3 leads to the following observations:

(a) The crack density of dry, as received, F6 sandstone is found to be zero in the three directions, in agreement with the SEM observations of the replica that show that the porosity almost entirely consists of rounded pores with no flat cracks. However, in thermally cracked F6 samples, the crack density is about 0.20 in all directions; application of a uniaxial stress entirely closes the cracks in the plane normal to the stress and generally decreases the crack density. The velocity data inverted by Crampin's model therefore yield sensible values of the crack density.

(b) The crack distribution of dry, as received, F32, F33 samples is almost isotropic, in agreement with the SEM observation of the replicas, where no preferred orientation of the cracks can be seen. Here, too, application of a uniaxial stress generally decreases the crack density and has a more pronounced effect on the cracks normal to the stress. Thermal cracking increases the crack density in all directions by about 50 percent.

(c) The crack density found for sample F7 is very high. Even though its numerical value (close to 1 ) is obviously unrealistic, it remains that SEM observation of sample F7 does indeed show that the porosity practically consists of microcracks only, with a large density. 

$E 1=0.10$

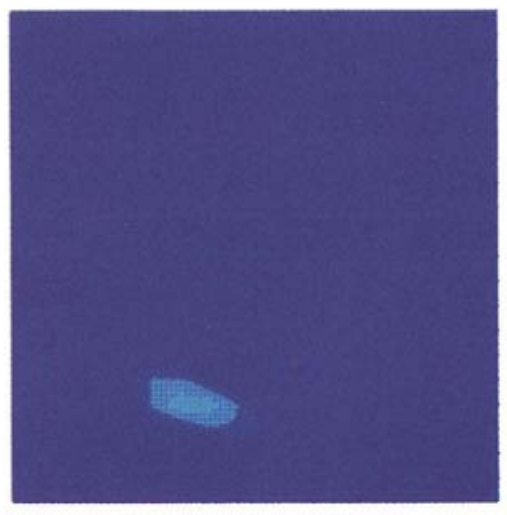

$E 1=0.20$

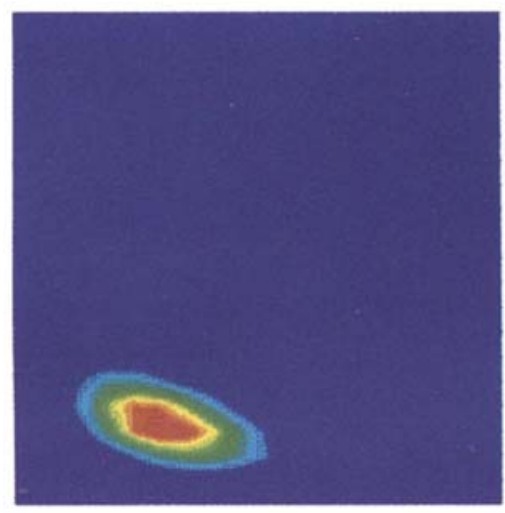

$E 1=0.30$

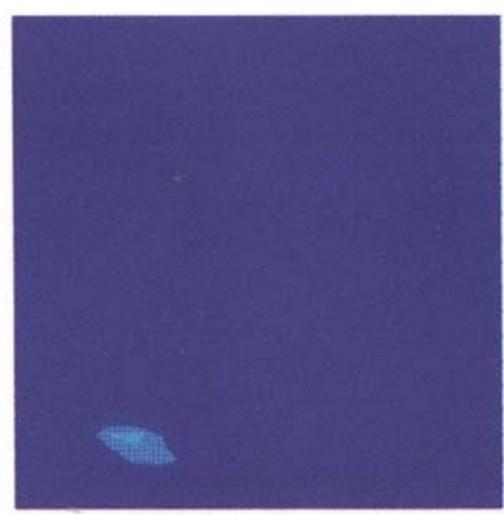

$E 1=0.15$

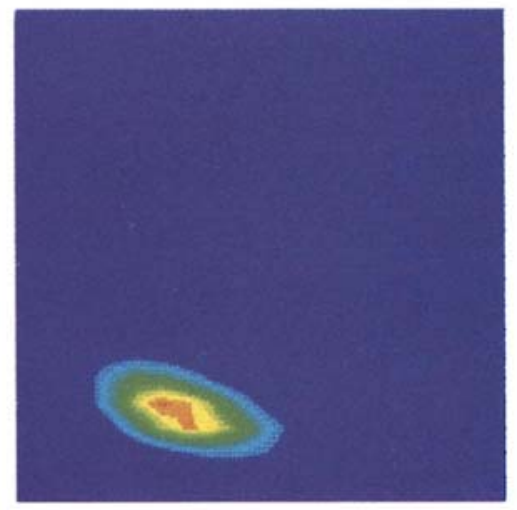

$\mathrm{E} 1=0.25$
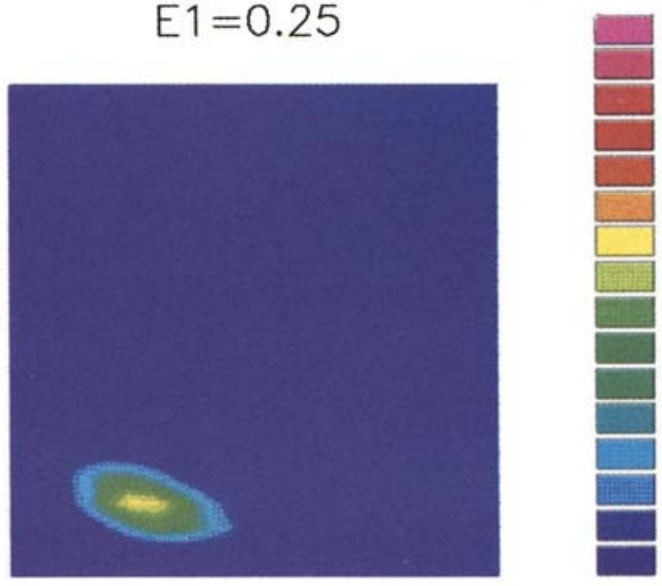

$\max$

0.90

$0.85-0.90$

$0.30-0.85$

$0.75-0.80$

$0.70-0.75$

$0.65-0.70$

$0.60-0.65$

$0.55-0.60$

$0.50-0.55$

$0.45-0.50$

$0.40-0.45$

$0.35-0.40$

$0.30-0.35$

$0.25-0.30$

$0.20-0.25$

$\min \quad 0.20$

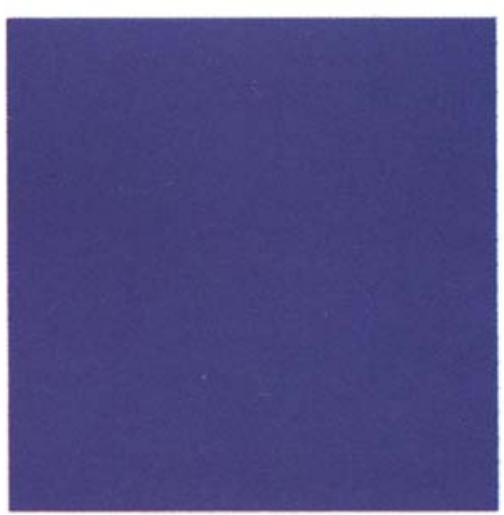

FIG. 10. Probability density contours for the crack densities. Sample F32 dry for $\sigma=0$. Each frame corresponds to different values of $\varepsilon_{1}$. The values of $\varepsilon$ corresponding to the probability maximum is found by visual inspection. The coordinates of the maximum (not shown here for clarity) give the values of $\varepsilon_{2}=0.15$ and $\varepsilon_{3}=0.30$. 
Crampin's model admittedly has shortcomings, among which the main ones are the fact that it does not take into account the interaction and connection of cracks and their aspect ratio. Nevertheless, its application to a realistic case yields results that qualitatively and sometimes quantitatively agree with the observations.

The fact that the aspect ratio of cracks is not taken into consideration is certainly a major drawback, especially when it comes to comparing the inverted crack density with the measured porosity, since rounded pores and flat cracks play different roles in the variation of velocities in dry and saturated samples. We can deal with this problem by applying the Kuster and Toksöz (1974) model (Zamora and Poirier, in preparation).

Table 3. Crack densities normal to the three orthogonal directions calculated by inversion of our experimental data with Crampin's model. The values are given for zero and maximum applied stress in vertical direction 3 , closing the horizontal cracks.

\begin{tabular}{|c|c|c|c|c|c|}
\hline Sample & State & Stress & $\varepsilon_{1}$ & $\varepsilon_{2}$ & $\varepsilon_{3}$ \\
\hline F32 & Dry & $\begin{array}{l}0.00 \\
5.88\end{array}$ & $\begin{array}{l}0.20 \\
0.15\end{array}$ & $\begin{array}{l}0.15 \\
0.15\end{array}$ & $\begin{array}{l}0.30 \\
0.05\end{array}$ \\
\hline F32 & Crac. Dry & $\begin{array}{l}0.00 \\
5.88\end{array}$ & $\begin{array}{l}0.45 \\
0.25\end{array}$ & $\begin{array}{l}0.45 \\
0.20\end{array}$ & $\begin{array}{l}0.50 \\
0.10\end{array}$ \\
\hline F33 & Dry & $\begin{array}{l}0.00 \\
7.84\end{array}$ & $\begin{array}{l}0.30 \\
0.20\end{array}$ & $\begin{array}{l}0.30 \\
0.25\end{array}$ & $\begin{array}{l}0.35 \\
0.20\end{array}$ \\
\hline F33 & Crac. Dry & $\begin{array}{l}0.00 \\
2.35\end{array}$ & $\begin{array}{l}0.60 \\
0.50\end{array}$ & $\begin{array}{l}0.45 \\
0.40\end{array}$ & $\begin{array}{l}0.60 \\
0.50\end{array}$ \\
\hline F6 & Dry & $\begin{array}{l}0.00 \\
7.84\end{array}$ & $\begin{array}{l}0.00 \\
0.00\end{array}$ & $\begin{array}{l}0.00 \\
0.00\end{array}$ & $\begin{array}{l}0.00 \\
0.00\end{array}$ \\
\hline F6 & Crac. Dry & $\begin{array}{l}0.00 \\
7.84\end{array}$ & $\begin{array}{l}0.20 \\
0.15\end{array}$ & $\begin{array}{l}0.15 \\
0.10\end{array}$ & $\begin{array}{l}0.20 \\
0.00\end{array}$ \\
\hline F7 & Dry & $\begin{array}{l}0.00 \\
3.14\end{array}$ & $\begin{array}{l}0.85 \\
0.65\end{array}$ & $\begin{array}{l}0.90 \\
0.70\end{array}$ & $\begin{array}{l}1.00 \\
0.55\end{array}$ \\
\hline
\end{tabular}

\section{ACKNOWLEDGMENTS}

We gratefully acknowledge the invaluable help that Bernard Zinszner and the I.F.P. laboratory of Rock Physics gave us in the course of this work. Much gratitude is due to Nader Dutta for his encouragement and helpful discussions. We owe many thanks to Albert Tarantola for his help with the inversion program.

This work was partially supported by CNRS (ERA 734 and ATP Geophysique Appliquée 1985). This is IPG contribution 1097 .

\section{REFERENCES}

Anderson, D. L., Minster, B., and Cole, D., 1974, The effect of oriented cracks on seismic velocities: J. Geophys. Res., 79, $4011-4015$.

Bonner, B. P., 1974, Shear wave birefringence in dilating granite: Geophys. Res. Lett., 1, 217-220.

Bourbie, T., Coussy, O., and Zinszner, B., 1986, Acoustics of porous media: Editions Technip.

Crampin, S., 1978, Seismic-wave propagation through a cracked solid: polarization as a possible dilatancy diagnostic: Geophys. J. R. Astr. Soc., 53, 467-496.

- 1987, Geological and industrial implications of extensivedilatancy anisotropy: Nature, 328, 491-496.

Ensley, R. A., 1985, Evaluation of direct hydrocarbon indicators through comparison of compressional- and shear-waves seismic data: a case study of the Myrnam gas field, Alberta: Geophysics, 50, 37-48.

Eshelby, J. D., 1957, The determination of the elastic field of an ellipsoidal inclusion, and related problems: Proc. Roy. Soc., A241, 376-396.

Garbin, H. D., and Knopoff, L., 1973, The compressional modulus of a material permeated by a random distribution of circular cracks: Quart. Appl. Math., 30, 453-464.

Garbin, H. D., and Knopoff, L., 1975a, The shear modulus of a material permeated by a random distribution of free circular cracks: Quart. Appl. Math., 33, 296-300.

- 1975 b, Elastic moduli of a medium with liquid-filled cracks: Quart. Appl. Math., 33, 301-303.

Gupta, I. N., 1973, Seismic velocities in rock subjected to axial loading up to shear fracture: J. Geophys. Res., 78, 6936-6942.

Hudson, J. A., 1981, Wave speeds and attenuation of elastic waves in material containing cracks: Geophys. J. R. Astr. Soc., 64, 133-150.

- 1988, Seismic wave propagation through material containing partially saturated cracks: Geophys. J., 92, 33-37.

Kranz, R. L., 1983, Microcracks in rocks: a review: Tectonophysics, 100, 449-480.

Kuster, G. T., and Toksöz, M. N., 1974, Velocity and attenuation of seismic waves in two-phase media: Part I. Theoretical formulations: Geophysics, 39, 587-606.

McCormack, M. D., Durbar, J. A., and Sharp, W. W., 1984, A case

\section{Anisotropy and Birefringence in Sandstone}

study of stratigraphic interpretation using shear and compressional seismic data: Geophysics, 49, 509-520.

Nur, A., 1971, Effects of stress on velocity anisotropy in rocks with cracks: J. Geophys. Res., 76, 2022-2034.

Nur, A., and Simmons, G., 1969, Stress-induced velocity anisotropy in rock: An experimental study: J. Geophys. Res., 74, 6667-6674.

O'Connell, R. J., and Budiansky, B., 1974, Seismic velocities in dry and saturated cracked solids: J. Geophys. Res., 35, 5412-5426.

Polskov, M. K., Brodov, L. J., Mironova, L. V., Michon, D. Garotta, R., Layotte, P. C., and Coppens, F., 1980, Utilisation combinée des ondes longitudinales et transversales en sismique reflexion: Geophys. Prosp., 28, 185-207.

Rai, C. S., and Hanson, K. E., 1988, Shear-wave velocity aniso- tropy in sedimentary rocks: A laboratory study: Geophysics, $\mathbf{5 3}$ 800-806.

Sayers, C. M., 1988, Inversion of ultrasonic wave velocity measurements to obtain the microcrack orientation distribution function in rocks: Ultrasonics, $26,73-77$.

Tarantola, A., 1987, Inverse problem theory: Elsevier Sci. Publ. Co. Tatham, R. H., 1982, $V_{p} / V_{s}$ and lithology: Geophysics, 47, 336-344.

Tilmann, S. E., and Bennett, H. F., 1973, Ultrasonic shear wave birefringence as a test of homogeneous elastic anisotropy: $J$. Geophys. Res., 78, 7623-7629.

Timur, A., and Toksöz, M. N., 1985, Downhole geophysical logging: Ann. Rev. Earth Planet. Sci., 13, 315-344. 